This is the submitted version, later published in Organic Chemistry Frontiers (RSC). The reference of the final edited and published work is Org. Chem. Front. 2021 DOI: 10.1039/D1QO00236H, and can be found at https:// pubs.rsc.org/en/content/articlelanding/2021/qo/d1qo00236h\#!divAbstract

\title{
ARTICLE
}

\section{Faster Palladium-Catalyzed Arylation of Simple Arenes in the presence of a methylketone: Beneficial effect of an a priori interfering solvent in $\mathrm{C}-\mathrm{H}$ activation}

Received 00th January 20xx, Accepted 00th January 20xx

DOI: $10.1039 / \times 0 \times x 00000 x$

\begin{abstract}
Vanesa Salamanca ${ }^{a}$ and Ana C. Albéniz ${ }^{a}$
The functionalization of simple arenes without coordinating directing groups is a challenge. Besides facing the task of cleaving the sluggish $\mathrm{C}-\mathrm{H}$ bond, the process is hampered by the weak coordinating ability of the arene $\pi$-system to the metal, which results in reactions that need a large excess of the reactant arene. Using a well-defined palladium complex with the ligand [2, 2'-bipyridin]-6(1H)-one, we have found that the use of a moderately coordinating solvent allows a decrease of the amount of arene used. Moreover, for the least coordinating arenes, the co-solvent produces a significant accelerating effect by altering the concentration and relative stability of relevant metal species in the catalytic cycle as well as the catalyst resting state. $t$-Butyl methyl ketone (pinacolone) is one of the most effective co-solvents: Even if the ketone $\mathrm{C}-\mathrm{H}$ bond cleaves easily, the final products are determined by the reductive elimination step (the product-forming step) so the target biaryl products are selectively observed.
\end{abstract}

\section{Introduction}

The build up of molecular complexity by direct functionalization of $\mathrm{C}-\mathrm{H}$ bonds of hydrocarbons is the ideal approach to a sustainable and green chemical synthesis. The enormous success and great utility of the large family of palladium-catalyzed cross coupling reactions encouraged many groups to develop reactions that use hydrocarbons instead on one, or two, of the conventional Pd-catalyzed coupling partners (typically an aryl halide and a main-group organometallic derivative). The effort paid and great advances in the field have been made in the last years. ${ }^{1}$ Now, the functionalization of $\mathrm{C}-\mathrm{H}$ bonds can be made regio-, ${ }^{2}$ and stereoselectively, ${ }^{3}$ both for $\mathrm{C}\left(\mathrm{sp}^{2}\right)-\mathrm{H}$ (arenes), ${ }^{4}$ and $\mathrm{C}\left(\mathrm{sp}^{3}\right)-\mathrm{H}$ bonds. $^{5}$

These successful reactions rely on the installation of suitable directing groups on the hydrocarbon that guarantee the preorganization for the required selectivity. They also increase the reactivity of the $\mathrm{C}-\mathrm{H}$ bond by making the activation intramolecular, paying the entropy price through precoordination of the directing group and lowering the overall energy requirements for $\mathrm{C}-\mathrm{H}$ cleavage (Scheme 1 ). This strategy is very precise and efficient but needs a prefuctionalization of the substrate and subsequent elimination of the directing group, therefore seriously eroding

\footnotetext{
a. IU CINQUIMA/Química Inorgánica. Universidad de Valladolid. 47071 Valladolid (Spain)

Electronic Supplementary Information (ESI) available: Experimental details, characterization, kinetic and X-ray structure determination data, selected spectra, microkinetic simulation and computational details including cartesian coordinates and calculated potential energies (PDF). See DOI: 10.1039/x0xx00000x
}

the sustainability and atom economy of the process even in the case of transient directing groups. ${ }^{6}$

The functionalization of hydrocarbons, and in particular arenes, without directing groups (sometimes called nondirected or rather non-chelate-assisted $\mathrm{C}-\mathrm{H}$ functionalization) is more challenging. ${ }^{7}$ Letting aside the subject of regioselectivity, the reactivity of simple arenes is much lower. The arene needs to coordinate to the metal and the substitution of almost any ligand by the weakly coordinating $\pi$ arene is not easy (Scheme 1). As a result a large excess or high concentrations of the arene (often as solvent) are frequently used to favor this step. ${ }^{8}$ Once coordinated, the $\mathrm{C}-\mathrm{H}$ cleavage follows and this is usually the highest energy step in the reaction profile. Both coordination issues and the actual $\mathrm{C}-\mathrm{H}$ activation need to be tackled to increase the reactivity of arenes with no directing groups.

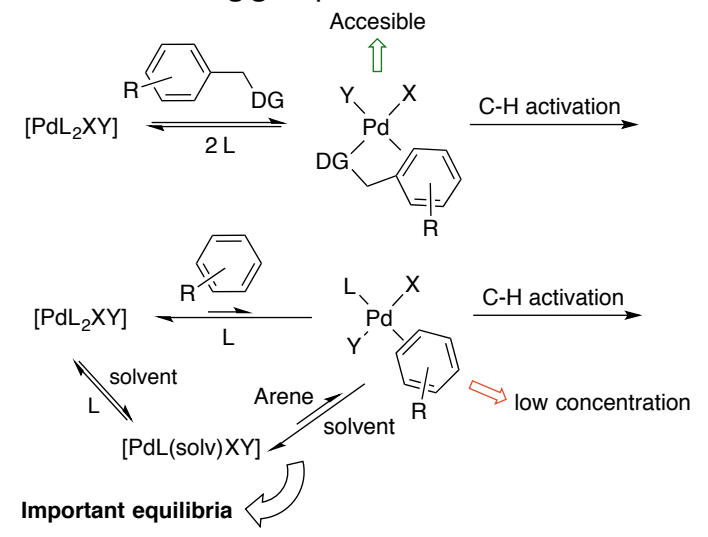

Scheme 1. Arene complexes formed before the actual $\mathrm{C}-\mathrm{H}$ cleavage and differences between non-chelate assisted coordination and arenes with directing groups (DG). 
In the case of the coupling reactions of ArX with arenes, few cases have been reported where the arene is either the limiting reactant or it has been used in moderate excess (two to fivefold). ${ }^{9}$ Many reactions of this type use a silver salt as a stoichiometric reagent, ${ }^{10}$ but, as elegantly proved by Larrosa, Sanford, and others, the silver salt can actually be responsible for the $\mathrm{C}-\mathrm{H}$ activation and form $\mathrm{AgAr}$ derivatives that transmetalate to palladium, in a type of reaction close to the conventional $\mathrm{C}-\mathrm{C}$ couplings. ${ }^{11}$ Some functionalizations of polyfluoroarenes $\left(\mathrm{C}_{6} \mathrm{~F}_{n} \mathrm{H}_{6-n}, \mathrm{n} \geq 3\right)$ are quite efficient with amounts of the fluorinated arene not too far from the stoichiometric ratio. ${ }^{12}$ However, it is necessary to point out that the $\mathrm{C}-\mathrm{H}$ cleavage of these arenes can occur without the involvement of the metal, just in the presence of base, ${ }^{13}$ so the formation of the Pd-fluoroaryl bond could occur by a attack of a transient carbanion to the metal.

The $\mathrm{C}-\mathrm{H}$ cleavage can be accelerated by the use of ligands that cooperate in this step through the assistance of a basic group in their structure in a CMD-type transition state (Fig. 1). We demonstrated this effect for the ligand [2, 2'-bipyridin]-6(1H)one (bipy-6-OH) and showed the acceleration of the arylation of pyridine with arylhalides (Fig. 1, a). ${ }^{14}$ This effect is also at play in the Pd-catalyzed functionalization of hydrocarbons with other pyridone derivatives as ligands, ${ }^{15}$ and with the N-monoprotected aminoacid ligands (MPAA) extraordinarily developed by the group of J. $-\mathrm{Q}$. Yu. ${ }^{16}$ The cooperating ligand leads to a lower energy transition state and does not need the precoordination of a base, such as a carboxylate, to the metal to reach it (Fig. 1, b). ${ }^{17}$ This is important to minimize the ligands that compete with the arene for coordination to the metal and it can be an additional advantage for the functionalization of simple arenes. a)

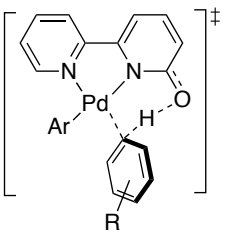

b)

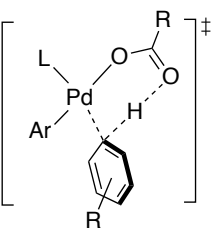

Fig. 1. Representation of CMD transition states for a $\mathrm{C}-\mathrm{H}$ activation by the basic group of bipy-6-O (a) or a carboxylate (b).

The election of a suitable solvent needed for the arylation of simple arenes using low or no-excess of arene is not trivial. Many of the commonly used solvents are usually better ligands than the arene and could be more reactive towards $\mathrm{C}-\mathrm{H}$ activation. However, we disclose here how an apparently troublesome solvent such as a methyl ketone (pinacolone) can be useful and even accelerate some of these reactions. Using the $\mathrm{Pd}$-(bipy-6-OH) catalytic system we have studied the arylation of monosubstituted arenes devoid of chelateassisting groups in the absence of silver salts. We showed before that this ligand enables the reaction for a few arenes as reactants and solvents. ${ }^{14}$ We show now that these reactions can be carried out with a lower concentration of the arene, an important issue for less available substrates, and we have found an unprecedented accelerating effect upon the addition of a solvent such as pinacolone. This effect can be only be understood by looking into the mechanism aspects of the arylation reaction.

\section{Results and Discussion}

\section{Arylation of arenes catalyzed by palladium bipy-6-OH complexes}

The reaction of an aryl iodide and different arenes enabled by the ligand [2, 2'-bipyridin]-6(1H)-one (bipy-6-OH) was probed using toluene as substrate and solvent. The reaction shown in Eq. 1 catalyzed by $\left[\mathrm{Pd}\left(\right.\right.$ bipy-6-OH) $\left.\mathrm{Br}\left(\mathrm{C}_{6} \mathrm{~F}_{5}\right)\right]$ (1) gives a $61 \%$ yield after $6 \mathrm{~h}$ (entry 1 , Table 1 ). The mixture of equimolar amounts of $\mathrm{Pd}(\mathrm{OAc})_{2}$ and bipy-6-OH can also be used as precatalyst and, even if a slower reaction is observed, high yields are eventually obtained (entry 2 , Table 1 ). The reaction needs the presence of bipy-6-OH (entry 3, Table 1) and other complexes with chelating $\mathrm{N}$-donors, including the analogous bipy-4-OH, are completely inefficient (entries 5-8 Table 1 ). $\mathrm{Cs}_{2} \mathrm{CO}_{3}$ was the base of choice since it works better that the soluble $\left(\mathrm{NBu}_{4}\right)_{2} \mathrm{CO}_{3}$ or the weaker $\mathrm{CsF}$ (Table S2, ESI).

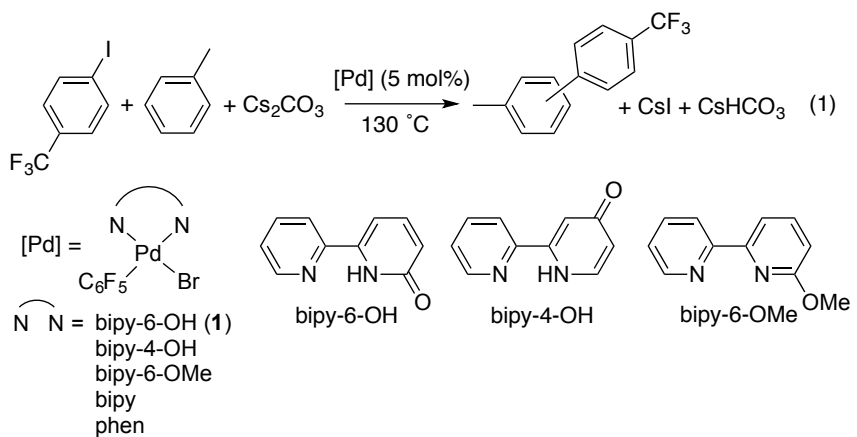

Table 1. Arylation of toluene with $p-\mathrm{CF}_{3} \mathrm{C}_{6} \mathrm{H}_{4} \mathrm{I}$ using different catalysts according to Eq. $1 .{ }^{\text {a }}$

\begin{tabular}{cccc}
\hline Entry & {$[\mathrm{Pd}]$} & $\begin{array}{c}\text { Crude yield, \% } \\
\text { (conv., \%) } 6 \mathrm{~h}^{\mathrm{b}}\end{array}$ & $\begin{array}{c}\text { Crude yield, \% } \\
\text { (conv, \%) } 24 \mathrm{~h}^{\mathrm{b}}\end{array}$ \\
\hline 1 & {$\left[\mathrm{Pd}(\mathrm{bipy}-6-\mathrm{OH}) \mathrm{Br}\left(\mathrm{C}_{6} \mathrm{~F}_{5}\right)\right](\mathbf{1})$} & $61(68)$ & $90(100)^{\mathrm{c}}$ \\
2 & {$\left[\mathrm{Pd}(\mathrm{OAc})_{2}\right]+$ bipy-6-OH } & $20(22)$ & $91(100)$ \\
3 & {$\left[\mathrm{Pd}(\mathrm{OAc})_{2}\right]$} & $0(0)$ & $0(0)$ \\
4 & - & $0(0)$ & $0(0)$ \\
5 & {$\left[\mathrm{Pd}(\right.$ bipy-4-OH $\left.) \mathrm{Br}\left(\mathrm{C}_{6} \mathrm{~F}_{5}\right)\right]$} & $0(0)$ & $0(0)$ \\
6 & {$\left[\mathrm{Pd}(\right.$ bipy-6-OMe $\left.) \mathrm{Br}\left(\mathrm{C}_{6} \mathrm{~F}_{5}\right)\right]$} & $0(0)$ & $0(0)$ \\
7 & {$\left[\mathrm{Pd}(\right.$ bipy $\left.) \mathrm{Br}\left(\mathrm{C}_{6} \mathrm{~F}_{5}\right)\right]$} & $0(0)$ & $1(5)$ \\
8 & {$\left[\mathrm{Pd}(\right.$ phen $\left.) \mathrm{Br}\left(\mathrm{C}_{6} \mathrm{~F}_{5}\right)\right]$} & $0(0)$ & $1(2)$ \\
\hline
\end{tabular}

${ }^{a}$ Reaction conditions: $p-\mathrm{CF}_{3} \mathrm{C}_{6} \mathrm{H}_{4} \mathrm{I}(51 \mu \mathrm{L}, 0.34 \mathrm{mmol})$, toluene $(3 \mathrm{~mL})$, [Pd] (5 mol $\%$ ), $\mathrm{Cs}_{2} \mathrm{CO}_{3}$ (222 mg, $0.68 \mathrm{mmol}$ ); 130 ㅇ. ${ }^{\mathrm{b}}$ Crude yields determined by ${ }^{19} \mathrm{~F}$ NMR of the reaction mixture. Mixture of regioisomers $0: \mathrm{m}: \mathrm{p}=1: 11: 5$. The reduction product of the aryliodide ( $\mathrm{ArH})$ and the homocoupling derivative ( $\mathrm{Ar}-\mathrm{Ar})$ are the observed byproducts. ${ }^{\mathrm{C}}$ Total conversion after $8 \mathrm{~h}$; isolated yield: $85 \%$.

The cooperating role of bipy-6-OH can be independently tested heating complex $2,{ }^{14}$ bearing the deprotonated ligand (bipy-6-O), in toluene (Scheme 2). The formation of the coupling product $\mathrm{C}_{6} \mathrm{~F}_{5}-\mathrm{C}_{6} \mathrm{H}_{4}-\mathrm{Me}$ supports that the oxygen of the pyridone fragment is capable of producing the $\mathrm{C}-\mathrm{H}$ activation in the absence of carbonate. The acid generated after the $\mathrm{C}-\mathrm{H}$ cleavage is responsible for the $\mathrm{C}_{6} \mathrm{~F}_{5} \mathrm{H}$ formed. The same result was obtained for benzonitrile. 


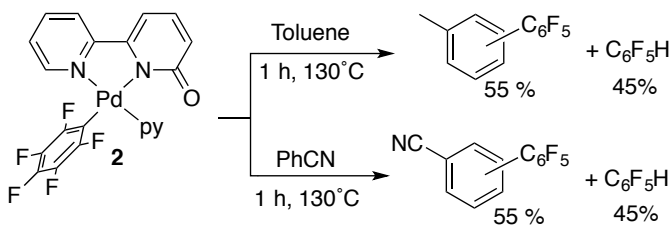

Scheme 2. C-H activation by the bipy-6-O ligand.

Using complex 1 and the conditions of Eq. 1, a range of arenes can be functionalized (Scheme 3). Five of these examples were reported by us before. ${ }^{14}$
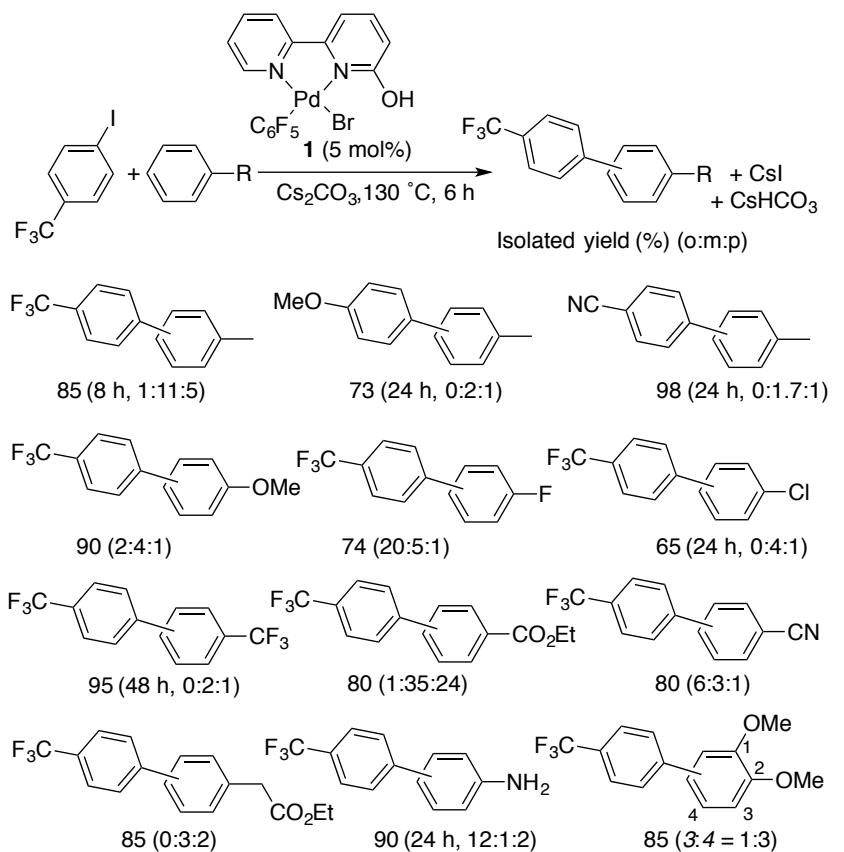

Scheme 3. Direct arylation of arenes by complex 1.

The work was carried out using $p-\mathrm{CF}_{3} \mathrm{C}_{6} \mathrm{H}_{4} \mathrm{l}$, which allows the easy monitorization and analysis of the reactions with different arenes by ${ }^{19} \mathrm{~F}$ NMR. Nonetheless two other aryl iodides with different electronic features $p-\mathrm{RC}_{6} \mathrm{H}_{4} \mathrm{I}(\mathrm{R}=\mathrm{CN}$, OMe) were tested with toluene, giving good results. Two or three regioisomers were obtained and the formation of the new $\mathrm{C}-\mathrm{C}$ bond in the meta position is preferred in most cases. Since the arenes tested are electronically very different the preference for the meta position might be steric in origin. Two exceptions of high selectivity for the ortho isomer were noted: fluorobenzene and aniline. In the first case this fact has already been described and it has been attributed to the stronger $\mathrm{M}-\mathrm{C}$ bond formed ortho to a fluorine atom. ${ }^{18}$ The second case, aniline, is currently under study in our group. It is clear and interesting that using complex $\mathbf{1}$ as catalyst no chelateassistance occurs for the arenes, $\mathrm{Ph}-\mathrm{R}$, that bear substituents that could play that role and be ortho-directing: $\mathrm{R}=$ COOEt and $\mathrm{CH}_{2}$ COOEt. Both arenes give meta (major) and para derivatives and no or a very little amount of the ortho regioisomer (Scheme 3).

In order to achieve the arylation reaction using a lower amount of arene we need a suitable solvent that does not interfere with the target reaction under the reaction conditions. Several high boiling solvents were tested and remarkable results were obtained (Table 2). A 1:1 (v/v) mixture of toluene and one of the amide or ketone solvents or DMSO leads to a faster reaction than using just toluene. It has to be noted that some of these solvents, specially DMF and the ketones, react at high temperatures with the arylhalide to give the reduction product $\mathrm{CF}_{3} \mathrm{C}_{6} \mathrm{H}_{5}$ and other decomposition products, whereas DMA and DMSO are less reactive. This can be seen in Table S10 (ESI) and has been studied in detail before. ${ }^{19}$ So, the most convenient solvent is not necessarily the least reactive and, regardless their intrinsic reactivity with the Arl, the target arylation of toluene is faster and produces the biaryl cross coupling product in good yields.

Table 2. Direct arylation of toluene with $p-\mathrm{CF}_{3} \mathrm{C}_{6} \mathrm{H}_{4} \mathrm{I}$ catalyzed by 1 using a co-solvent. ${ }^{\text {a }}$

\begin{tabular}{cccc}
\hline Entry & Solvent (1:1) & Ar-Tol (\%), 90 min & Ar-Tol (\%), $6 \mathrm{~h}^{\mathrm{b}}$ \\
\hline 1 & Ph-Me & - & 61 \\
2 & Ph-Me/Pinacolone & $89^{\mathrm{c}}$ & \\
3 & Ph-Me/DMSO & 74 & 90 \\
4 & Ph-Me/DMA & 81 & $94^{\mathrm{d}}$ \\
5 & Ph-Me/DMF & $83^{\mathrm{c}, \mathrm{e}}$ & \\
6 & Ph-Me/butanone & 73 & $86^{\mathrm{f}}$ \\
7 & tert-AmylOH & 18 & 37 \\
\hline
\end{tabular}

${ }^{a}$ Reaction conditions: 1 (0.017 mmol), $\mathrm{Cs}_{2} \mathrm{CO}_{3}$ (0.68 mmol), $p-\mathrm{CF}_{3} \mathrm{C}_{6} \mathrm{H}_{4} \mathrm{l}(0.34$ $\mathrm{mmol})$, toluene $(1.5 \mathrm{~mL})$, co-solvent $(1.5 \mathrm{~mL}) ; 130 \stackrel{\circ}{\circ}$. ${ }^{\mathrm{b}}$ Crude yields determined by ${ }^{19} \mathrm{~F}$ NMR ( $\mathrm{CF}_{3}$ region) of the crude mixture. ${ }^{\mathrm{c}}$ Total conversion. ${ }^{\mathrm{d}}$ Isolated yield $90 \%$ (o:m:p = 1:4:3). ${ }^{\mathrm{e}}$ Isolated yield $77 \%$ (o:m:p = 1:2:1.5). ${ }^{\mathrm{f}}$ Isolated yield $80 \%$ (o:m:p = 1:4:2)

From the solvents in Table 2, tert-butyl methyl ketone (pinacolone) was chosen for our studies since it leads to the most efficient reaction (entry 2, Table 2) and it is environmentally friendlier than the amides or DMSO. ${ }^{20}$ The behavior of pinacolone is also intriguing since this solvent may seem the poorest choice in arene activation, the $\mathrm{C}-\mathrm{H}$ bond of a methylketone breaking easily just by deprotonation with base. Indeed, this happens in the absence of toluene and $\mathrm{ArCH}_{2} \mathrm{C}(\mathrm{O})^{\mathrm{t}} \mathrm{Bu}$ was observed (see ESI). However, this product was not found in the arylation of arenes in arene/pinacolone $(1 / 1)$. We believe the reason for this selectivity is the higher energy of the reductive elimination $C\left(s p^{3}\right)-C\left(s p^{2}\right)$, the productforming step, as will be analyzed below.

Table 3 collects the yields and reaction times of the arylation of different arenes with $p-\mathrm{CF}_{3} \mathrm{C}_{6} \mathrm{H}_{4} \mathrm{l}\left(p-\mathrm{CF}_{3} \mathrm{C}_{6} \mathrm{H}_{4} \mathrm{Br}\right.$ for entries 3 and 4$)$ using the arene as solvent or a $1: 1(\mathrm{v} / \mathrm{v})$ mixture of arene:pinacolone. All the reactions give good yields using pinacolone as a component of the solvent mixture and the isomer distribution in the coupling products is similar to that obtained when the arene is used as the only solvent. However, whereas the reaction rate is significantly increased for those arenes that bear less coordinating substituents than pinacolone (entries 1-10, Table 3 ), the reaction times cannot be reduced for the most coordinating arenes (entries 11-18, 
Table 3). The accelerating effect of the addition of pinacolone is not caused exclusively by an increase of the polarity of the reaction media, as it happens for toluene/pinacolone vs toluene, for example: The polarity of $\mathrm{PhCF}_{3}\left(\mathrm{E}_{\mathrm{T}}{ }^{30}=38.5\right)$ and PhCOOEt $\left(\mathrm{E}_{\mathrm{T}}{ }^{30}=38.1\right)$ is similar and the addition of pinacolone accelerates the reaction only in the first case (entries 9 and 10 vs entries 13 and 14 , Table 3$)^{21}$

Table 3. Direct arylation reaction of arenes $(\mathrm{Ph}-\mathrm{R})$ with $p-\mathrm{CF}_{3} \mathrm{C}_{6} \mathrm{H}_{4} \mathrm{I}$ catalyzed by $\mathbf{1}$ using the arene as solvent vs a mixture of arene/pinacolone. ${ }^{a}$

\begin{tabular}{|c|c|c|c|}
\hline Entry & Solvent & Crude yield \% $(\mathrm{h})^{\mathrm{b}}$ & $\begin{array}{c}\text { Isolated yield } \\
(o: m: p)^{b}\end{array}$ \\
\hline 1 & Ph-Me & $90(8 \mathrm{~h})$ & $85(1: 11: 5)$ \\
\hline 2 & $\mathrm{Ph}-\mathrm{Me} /$ pinacolone & $89(1.5 \mathrm{~h})$ & $86(1: 5: 3)$ \\
\hline $3^{c}$ & $\mathrm{Ph}-\mathrm{Me}$ & $35(6 \mathrm{~h}), 56(24 \mathrm{~h})$ & $50(1: 6: 3)$ \\
\hline $4^{c}$ & $\mathrm{Ph}-\mathrm{Me} /$ pinacolone & $40(0.5 \mathrm{~h}), 90(6 \mathrm{~h})$ & $88(1: 5: 3)$ \\
\hline 5 & $\mathrm{Ph}-\mathrm{OMe}$ & 19 (2 h), 96 (6 h) & $90(2: 4: 1)$ \\
\hline 6 & $\mathrm{Ph}-\mathrm{OMe} /$ pinacolone & $94(2 \mathrm{~h})$ & $90(1.5: 2: 1)$ \\
\hline 7 & $\mathrm{Ph}-\mathrm{F}$ & $30(1 \mathrm{~h}), 77(6 \mathrm{~h})$ & $74(20: 5: 1)$ \\
\hline 8 & Ph-F/pinacolone & $85(1 \mathrm{~h})$ & $84(13: 2: 1)$ \\
\hline 9 & $\mathrm{Ph}-\mathrm{CF}_{3}$ & $-^{d}$ & $95(48 h)(0: 2: 1)$ \\
\hline 10 & $\mathrm{Ph}-\mathrm{CF}_{3} /$ pinacolone & ${ }_{-}^{d}$ & $95(24 h)(0: 2: 1)$ \\
\hline 11 & $\mathrm{Ph}-\mathrm{CN}$ & $31(2 \mathrm{~h}), 83(6 \mathrm{~h})$ & $80(6: 3: 1)$ \\
\hline 12 & $\mathrm{Ph}-\mathrm{CN} /$ pinacolone & $18(2 \mathrm{~h}), 80(24 \mathrm{~h})$ & $78(6: 3: 1)$ \\
\hline 13 & $\mathrm{Ph}-\mathrm{CO}_{2} \mathrm{Et}$ & $60(0.5 \mathrm{~h}), 84(6 \mathrm{~h})$ & $80(1: 35: 24)$ \\
\hline 14 & $\mathrm{Ph}-\mathrm{CO}_{2} \mathrm{Et} /$ pinacolone & $44(0.5 \mathrm{~h}), 81(6 \mathrm{~h})$ & $75(1: 6: 2)$ \\
\hline 15 & py & $57(0.5$ h), $94(1 \mathrm{~h})$ & $90(3: 33: 1)$ \\
\hline 16 & py/pinacolone & $50(0.5 \mathrm{~h}), 95(1 \mathrm{~h})$ & $90(3: 33: 1)$ \\
\hline 17 & $\mathrm{Ph}-\mathrm{NH}_{2}$ & $40(6 \mathrm{~h}), 92(24 \mathrm{~h})$ & $90(12: 1: 2)$ \\
\hline 18 & $\mathrm{Ph}-\mathrm{NH}_{2} /$ pinacolone & $57(6 h), 98(24 h)$ & $92(18: 1: 1)$ \\
\hline
\end{tabular}

${ }^{a}$ Reaction conditions: 1 (0.017 mmol), $\mathrm{Cs}_{2} \mathrm{CO}_{3}(0.68 \mathrm{mmol}), p-\mathrm{CF}_{3} \mathrm{C}_{6} \mathrm{H}_{4} \mathrm{l}(0.34$ $\mathrm{mmol})$; arene $(1.5 \mathrm{~mL})$, pinacolone $(1.5 \mathrm{~mL}) ; 130 \stackrel{\circ}{\circ} \mathrm{C} ; \mathrm{py}=$ pyridine. ${ }^{\mathrm{b}}$ Yields and regioselectivities were determined by integration of the $\mathrm{CF}_{3}$ signals in ${ }^{19} \mathrm{~F} \mathrm{NMR} .{ }^{\circ}$ $\mathrm{CF}_{3} \mathrm{C}_{6} \mathrm{H}_{4} \mathrm{Br}(0.34 \mathrm{mmol})$ was used. ${ }^{\mathrm{d}}$ The large amount of $\mathrm{PhCF}_{3}$ does not allow to determine the crude yields.

Further reduction of the amount of arene is possible to almost the stoichiometric ratio for the coordinating aniline and also for phenol (Eq. 2). For other arenes 10 equivalents are needed. In most cases the yields are just slightly lower that those collected in Table 3 for the 1:1 arene/pinacolone ratio (i.e. about 40 equivalents of arene), so the reactions are synthetically useful (see ESI for details).

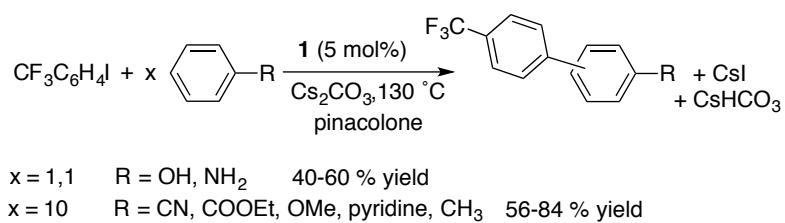

$\mathrm{x}=1,1 \quad \mathrm{R}=\mathrm{OH}, \mathrm{NH}_{2} \quad 40-60 \%$ yield

$\mathrm{x}=10 \quad \mathrm{R}=\mathrm{CN}, \mathrm{COOEt}$, OMe, pyridine, $\mathrm{CH}_{3} \quad 56-84 \%$ yield

\section{$\mathrm{C}-\mathrm{H}$ activation of the solvent vs the arene and $\mathrm{C}-\mathrm{C}$ bond formation.}

A methyl ketone such as pinacolone, is a more reactive substrate than the arene towards $\mathrm{C}-\mathrm{H}$ activation. However, the ketone coupling product, $\mathrm{Ar}-\mathrm{CH}_{2} \mathrm{C}(\mathrm{O})^{\mathrm{t}} \mathrm{Bu}$ is not formed in the reactions in Table 3 and, in the case of toluene, only when a lower amount the arene is present, $\mathrm{Ar}-\mathrm{CH}_{2} \mathrm{C}(\mathrm{O})^{\mathrm{t}} \mathrm{Bu}$ is detected as a minor product (toluene/pinacolone volume ratio $<1 / 4$ or toluene/ArX mol ratio $\leq 16 / 1$ ). The reason for the selective formation of the arene arylation products must be in the product-forming step from an intermediate complex $\mathrm{Cs}\left[\mathrm{Pd}\left(\right.\right.$ bipy-6-O) $\left.\left(p-\mathrm{CF}_{3} \mathrm{C}_{6} \mathrm{H}_{4}\right) \mathrm{R}\right]$ bearing both hydrocarbyl fragments as shown in Fig. 2, a. The reductive elimination reactions that involve $\mathrm{M}-\mathrm{C}\left(\mathrm{sp}^{3}\right)$ bonds are generally slower that those for $\mathrm{M}-\mathrm{C}\left(\mathrm{sp}^{2}\right)$ bonds, ${ }^{22}$ and Fig. 2a shows a comparison of the calculated barrier for the reductive elimination of the arylated toluene or the arylated pinacolone products where a higher barrier was found for the $\mathrm{C}\left(\mathrm{sp}^{2}\right)-\mathrm{C}\left(\mathrm{sp}^{3}\right)$ bond formation. The same trend was also observed for the barrier of the reductive elimination from a neutral complex bearing the protonated ligand $\left[\mathrm{Pd}(\right.$ bipy-6-OH $\left.)\left(p-\mathrm{CF}_{3} \mathrm{C}_{6} \mathrm{H}_{4}\right) \mathrm{R}\right]$ (see ESI). Moreover, the protonation of the enolate moiety is an easy process, ${ }^{23}$ and this can occur faster than the $\mathrm{C}-\mathrm{C}$ bond formation, making the ketone $\mathrm{C}-\mathrm{H}$ activation unproductive.

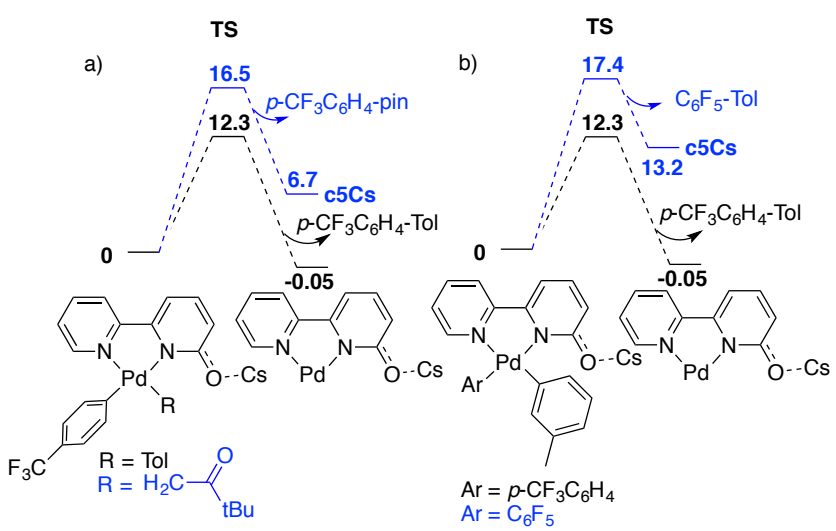

Fig. 2. Free energy barriers for the reductive elimination step. Energies in $\mathrm{kcal} \mathrm{mol}^{-1}$.

Taking advantage of this, we carried out the experiment shown in Eq. 3. The arylation of toluene in a mixture of toluene/acetone- $d_{6}$ provides a deuterium source and a possible H/D scrambling.

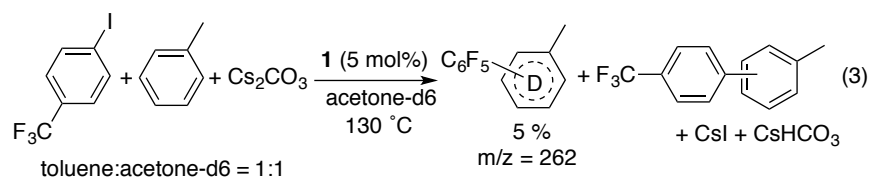

The reaction leads to the $\mathrm{p}-\mathrm{CF}_{3}-\mathrm{C}_{6} \mathrm{H}_{4}$-Tol coupling product with no deuterium incorporation, showing that the toluene $\mathrm{C}-\mathrm{H}$ activation is irreversible in the catalytic reaction and that the reductive elimination occurs efficiently. However, the product $\mathrm{C}_{6} \mathrm{~F}_{5}$-Tol, formed by the transformation of the precatalyst, is completely deuterated in the ring. The reason for this is a higher reductive elimination barrier for the $\mathrm{C}_{6} \mathrm{~F}_{5}$ and tolyl fragments (Fig. 2b, blue); because of this higher energy barrier, the protonation of the tolyl group in the electron rich bisaryl 
complex $\mathrm{Cs}\left[\mathrm{Pd}\left(\right.\right.$ bipy-6-O) $\left.(\mathrm{Tol})\left(\mathrm{C}_{6} \mathrm{~F}_{5}\right)\right]$ can be competitive making the $\mathrm{C}-\mathrm{H}$ activation of toluene reversible in this case.

This experiment unequivocally shows that the ketone $C-D$ bond is reversibly cleaved but the $\mathrm{C}\left(\mathrm{sp}^{2}\right)-\mathrm{C}\left(\mathrm{sp}^{3}\right)$ reductive elimination does not occur and the aryl-ketone coupling product was not observed.

\section{Experimental information on the catalytic reaction and relevant} palladium species under catalytic conditions.

In order to understand the accelerating effect of pinacolone, we gathered some experimental information on the arylation of toluene both in toluene as solvent or in the mixture toluene/pinacolone (Eq. 4).

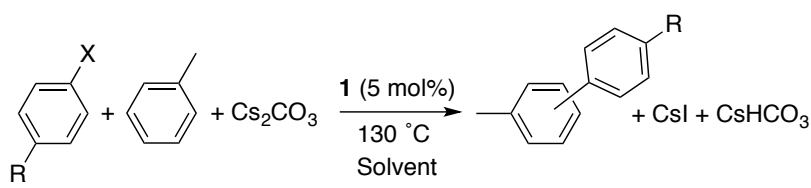

Solvent $=$ toluene or toluene/pinacolone $(1 / 1)$

We could not collect exhaustive kinetic data by monitorization of these reactions at short time intervals. The reactions are carried out at $130{ }^{\circ} \mathrm{C}$ in tightly closed or sealed flasks and we could not sample the reactions often enough without seriously disturbing the system. Therefore, the kinetic information given here corresponds to parallel experiments with different initial concentrations of the components, checked at the same reaction times (see ESI for details). However limited, the results are quite clear. In both solvents, the arylation of toluene with complex $\mathbf{1}$ is first order in catalyst (Tables S5 and S6, ESI) and independent of the arylhalide concentration (Table S3, ESI). The latter was tested for different ArX, from $p$ $\mathrm{CF}_{3} \mathrm{C}_{6} \mathrm{H}_{4} \mathrm{l}$, prone to undergo oxidative addition, to the more reluctant bromide $p-\mathrm{CF}_{3} \mathrm{C}_{6} \mathrm{H}_{4} \mathrm{Br}$ or $p-\mathrm{OMeC}_{6} \mathrm{H}_{4} \mathrm{l}$. Experiments changing the relative ratio toluene:pinacolone showed that the reaction rate increases in an almost linear fashion upon increasing the amount of toluene from an ArX:toluene ratio 8:1 to $25: 1$ indicating a first order dependence in this range. A further increase of the toluene concentration shows no increase in the rate as expected from a saturation behavior (Table S7, ESI). We checked how the free halide concentration affects the reactions and found that the addition of a small amount of $\mathrm{NBu}_{4} \mathrm{l}$ (about $10 \mathrm{~mol} \%$ ) has a stronger decelerating effect in toluene than in toluene/pinacolone where the decrease in rate is almost negligible. These are qualitative results since the presence of cesium salts in the reaction medium may lead to ion exchange and the formation of some insoluble Csl which makes the actual concentration of iodide different from the intended one. In any case, an excess of halide ( 2 equivalents) halts the reaction in both solvents and drives the transformation of the aryl halide to $\mathrm{ArH}$ and $\mathrm{Ar}-\mathrm{Ar}$ decomposition products (Table S8, ESI). The kinetic isotope effect was determined in parallel experiments in separate flasks using toluene in one of them and deuterated toluene in the other. A distinct KIE was observed in the experiments showing that the $\mathrm{C}-\mathrm{H}$ cleavage is the rate-limiting step of the reaction (Eq. 5). However, the experimental KIE values are lower than the expected one for the $\mathrm{C}-\mathrm{H}$ activation as the only rate-limiting step $\left(\mathrm{KIE}_{\text {calc }}=3.64\right.$, by DFT methods, see $\left.\mathrm{SI}\right)$, especially in toluene. This is an indication that there is a step in the reaction before the actual $\mathrm{C}-\mathrm{H}$ cleavage also important in controlling the rate (see below). ${ }^{24}$

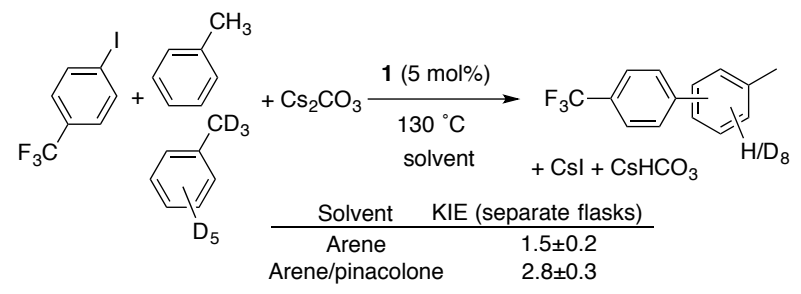

We also gathered information about the behavior of complex $\mathbf{1}$ in different conditions. This is the precatalyst we used but it is also a good model to analyze the species that are formed in the catalysis. When compared to other aryls, the pentafluorophenyl group imparts a higher stability to its palladium derivatives while still showing the same reactivity towards $\mathrm{C}-\mathrm{C}$ bond formation. This has been shown for a variety of Pd-mediated processes, ${ }^{25}$ and also in our former work on the direct arylation of pyridine (see also Scheme 2 ). ${ }^{14}$

When a solution of complex 1 in a 1:1 mixture of toluene/pinacolone is treated with $\mathrm{Cs}_{2} \mathrm{CO}_{3}$, a mixture of the putative solvento complex $\mathbf{3}$ and $\mathbf{4}$ is formed (3:4 = 11:1 mol ratio) (Scheme 4 and Fig. S5, ESI). Small amounts of water in the solvent account for the formation of the dimer $\mathbf{4}$, which is less soluble and crystallized as a yellow solid upon attempts at isolation of $\mathbf{3}$.

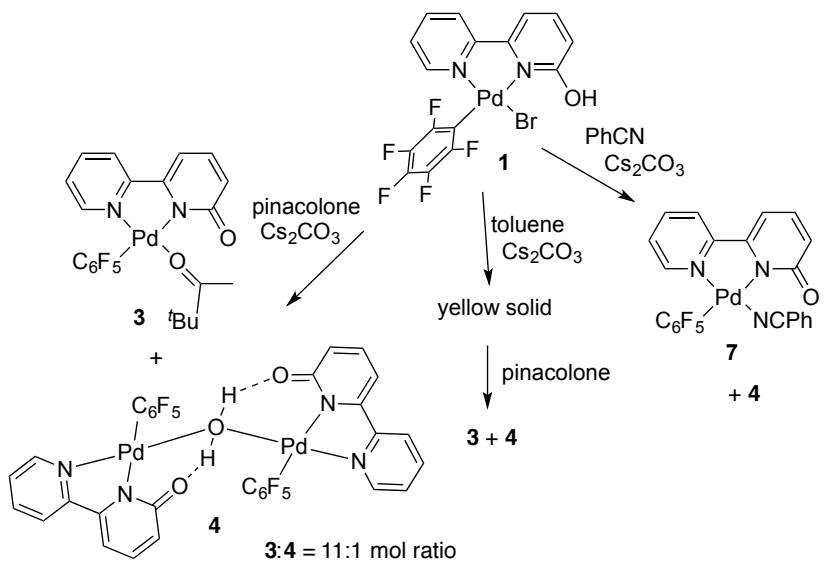

Scheme 4. Relevant palladium species from complex 1.

The X-ray molecular structure of $\mathbf{4}$ is depicted in Fig. 3 and shows a dimeric structure with a $C_{2}$ symmetry. This is consistent with the solution ${ }^{1} \mathrm{H}$ and ${ }^{19} \mathrm{~F}$ NMR spectral patterns, the latter showing restricted rotation of the $\mathrm{C}_{6} \mathrm{~F}_{5}$ groups (Fig. $\mathrm{S} 39, \mathrm{ESI}$ ). The bridging group could be described as a water molecule $\mathrm{H}$-bonded to the oxygen atoms of the pyridone ligands, which is an unprecedented arrangement in palladium chemistry. However, in the solid state the $\mathrm{O}$ (pyridone)- $\mathrm{H}-$ $\mathrm{O}$ (water) distances for both water $\mathrm{O}-\mathrm{H}$ bonds are different, so the structural motive could also be described as a hydroxo bridge $\mathrm{H}$-bonded to a bipy-6-O ligand and a protonated bipy-6$\mathrm{OH}$. Be as it may, the symmetric structure in solution points to 
an $\mathrm{H}$-bonded water or a fast $\mathrm{H}$ exchange between $\mathrm{O}$ (pyridone) and $\mathrm{O}$ (water) leading to a sharp resonance at $13.5 \mathrm{ppm}$ in the ${ }^{1} \mathrm{H}$ NMR. The presence of additional water in a dichloromethane solution of $\mathbf{4}$ brings about the cleavage of the bridge and the formation of $\left[\mathrm{Pd}\left(\right.\right.$ bipy-6-O) $\left.\left(\mathrm{C}_{6} \mathrm{~F}_{5}\right)\left(\mathrm{H}_{2} \mathrm{O}\right)\right](5$, see ESI).

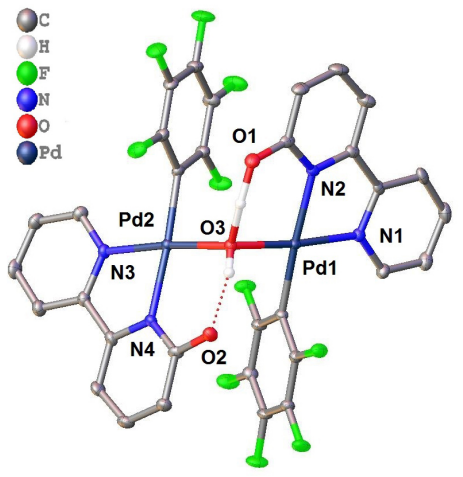

Fig. 3. Molecular structure of 4 (ORTEP plot, $30 \%$ probability). Hydrogen atoms, except for those of the bridging fragment, and the two $\mathrm{CH}_{2} \mathrm{Cl}_{2}$ molecules that co-crystalize are omitted for clarity.

Cleavage of the water bridge occurs only upon addition of a large excess of pinacolone to a solution of complex 4 in $\mathrm{CD}_{2} \mathrm{Cl}_{2}$ and the new species formed was attributed to the pinacolone aduct 3 (Fig. S6-S8, ESI). The large excess of pinacolone does not allow to identify the coordinated ketone, which may even undergo fast exchange with the free ketone. When the isolated $\mathbf{4}$ was dissolved in toluene/pinacolone, the mixture of $\mathbf{3}$ and $\mathbf{4}$ was formed in the same ratio as observed in the experiment in Scheme 4. Therefore the pentafluorophenyl complex $\mathbf{3}$ at the beginning of the reaction and the analogous [Pd(bipy-6-O)Ar(pinacolone)] intermediate, are the likely predominant species under catalytic conditions in the mixture toluene/pinacolone.

The formation of the pinacolone complex is driven by the insoluble byproduct $\mathrm{CsBr}$. In fact, the equilibria depicted in Scheme 5 favors the halogen complex. Thus, the mixture of $\mathbf{1}$ with $\left(\mathrm{NBu}_{4}\right)_{2} \mathrm{CO}_{3}$ as a base in toluene/pinacolone leads to complex 6, as observed by ${ }^{19} \mathrm{~F} \mathrm{NMR} .{ }^{26}$ However, when $\mathrm{Cs}_{2} \mathrm{CO}_{3}$ was used, the formation of the insoluble $\mathrm{CsBr}$ shifts the equilibrium towards 3 (and 4) (Scheme 5, a). An estimate of the equilibrium constant for the iodo case was made by preparing complex $\mathbf{3}$ in a toluene/pinacolone solution and adding a known amount of the soluble iodide salt $\left(\mathrm{NBu}_{4}\right) \mathrm{I}$ as shown in Scheme $5, b$. This leads to a value of $K=1.6 \pm 0.1 \times 10^{-4}$.

a)
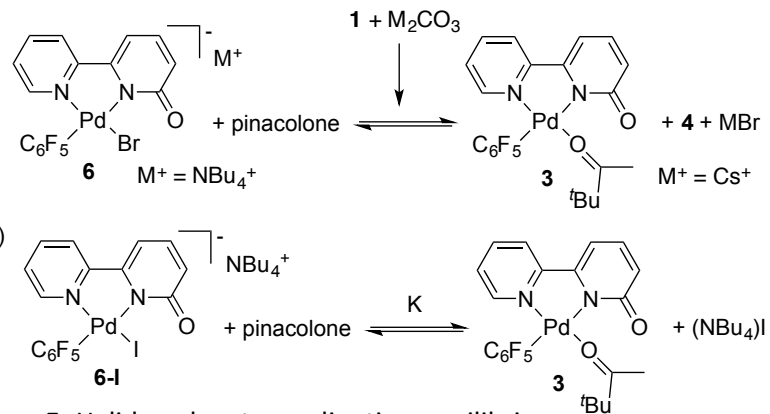

Complex $\mathbf{1}$ is soluble in toluene only at temperatures higher than $90{ }^{\circ} \mathrm{C}$, so it is not possible to get much information in this medium. Nonetheless the mixture of 1 and $\mathrm{Cs}_{2} \mathrm{CO}_{3}$ in toluene was sonicated and the pale yellow complex $\mathbf{1}$ transformed into a bright yellow solid. Complex 4 was detected in the supernatant solution. Upon addition of pinacolone the yellow solid dissolved and the mixture of 3 and 4 (3:4 = 11:1 mol ratio) was identified (Scheme 4$)$. This is consistent with the formation of complex $\mathrm{Cs}\left[\mathrm{Pd}\right.$ (bipy-6-O) $\left.\mathrm{Br}\left(\mathrm{C}_{6} \mathrm{~F}_{5}\right)\right]$ (Cs-6) as the bright yellow solid. The addition of $\mathrm{Cs}_{2} \mathrm{CO}_{3}$ to 1 was also carried out in benzonitrile where the formation of a new complex, 7, was observed, as well as complex 4 and other minor unidentified species by ${ }^{19} \mathrm{~F}$ NMR (see Fig. S10, ESI). Complex 7 was tentatively assigned to the benzonitrile solvento complex (Scheme 4); the addition of a silver salt does not produce any change in the spectrum, which supports the absence of the halide in the palladium coordination sphere.

All these experiments show that the formation of the solvento complexes with pinacolone or a moderately coordinating arene is favorable in the presence of a cesium cation (leading to the insoluble CsX salts) and these are the expected main palladium species under catalytic conditions. It is worth noticing that this behavior was previously observed for pyridine where complexes [Pd(bipy-6-O)Ar(pyridine)] $(\mathrm{Ar}=$ $\left.\mathrm{C}_{6} \mathrm{~F}_{5}, 2 ; p-\mathrm{CF}_{3} \mathrm{C}_{6} \mathrm{H}_{4}\right)$ were characterized. ${ }^{14}$ Although minor, the water complex 4 is ubiquitous, the high water coordination affinity probably derived from the formation of stabilizing $\mathrm{H}$ bonds. We learnt that 4 is catalytically competent and when it was used as precatalyst (4, $2.5 \mathrm{~mol} \%)$ under the conditions of Eq. 1, it gave $45 \%$ of the coupling products after $6 \mathrm{~h}$. The ligand in complex 4 also enables the $\mathrm{C}-\mathrm{H}$ activation step as shown in Eq. 6. If species analogous to $\mathbf{4}$ are formed in the catalytic reactions they will most probably be outside the catalytic cycle but, according to these experiments, they are not a dead end and can reenter the cycle.

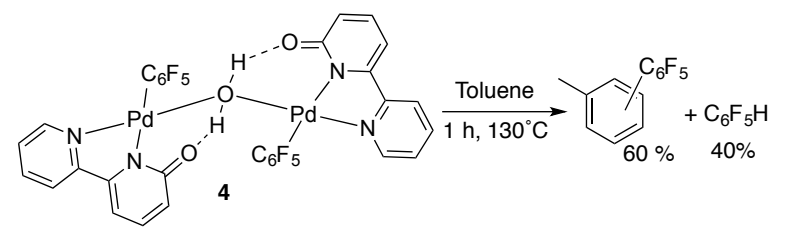

Modeling the arylation of toluene with complex 1 using DFT and a microkinetic simulation: Influence of the reaction media.

All the experimental data are consistent with the mechanism for the arylation of arenes, using toluene as a model, depicted in Scheme 6. This is a $\mathrm{Pd}(0) / \mathrm{Pd}(\mathrm{II})$ cycle analogous to the one that operates in the arylation of pyridine with the Pd-bipy-6$\mathrm{OH}$ system that we have studied before. ${ }^{14}$ Intermediates $\mathbf{B}$ and C are analogous to complexes $\mathbf{6}$ and $\mathbf{3}$ respectively. 


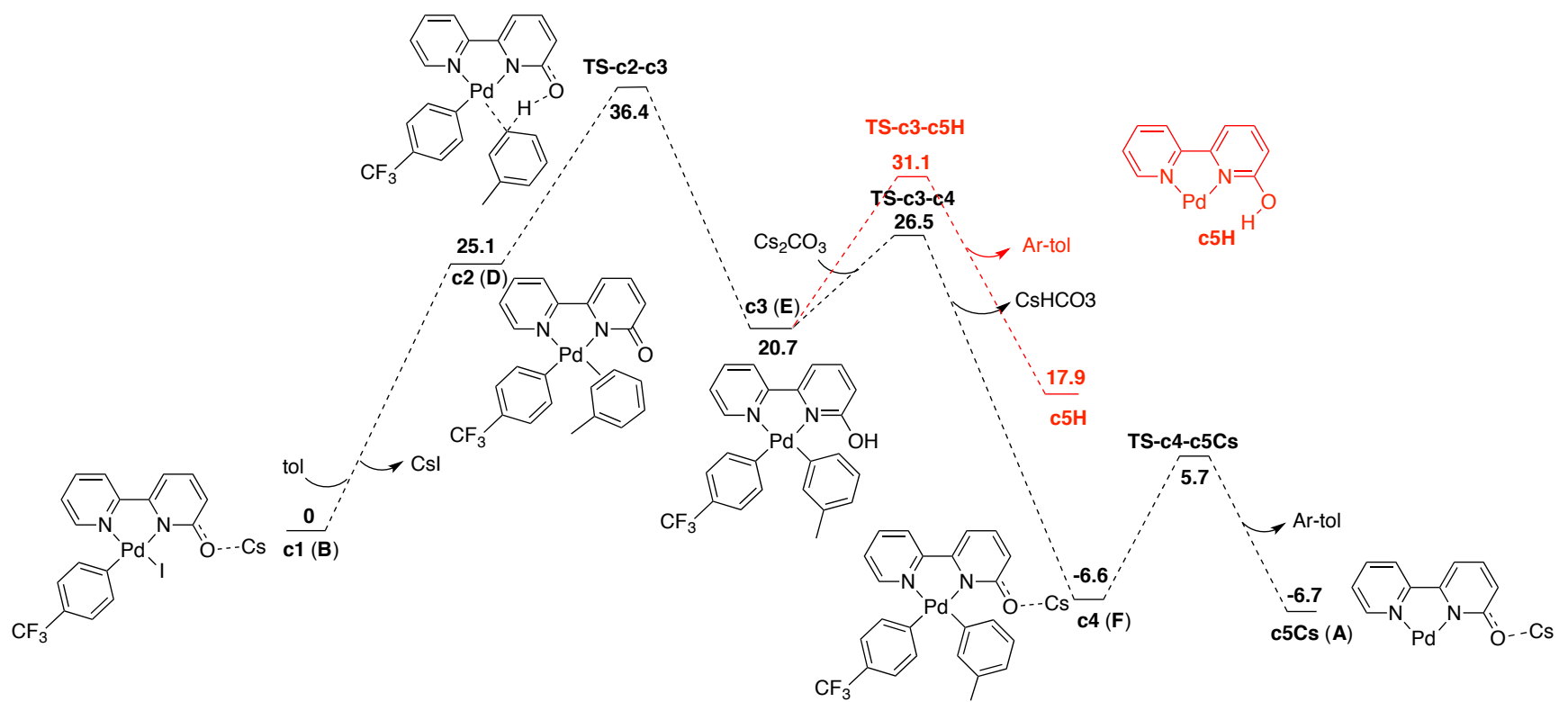

Fig. 4. Free-energy profile for the Pd-catalyzed arylation of toluene assisted by the ligand bipy-6-O in toluene as solvent. Energies in kcal mol ${ }^{-1}$

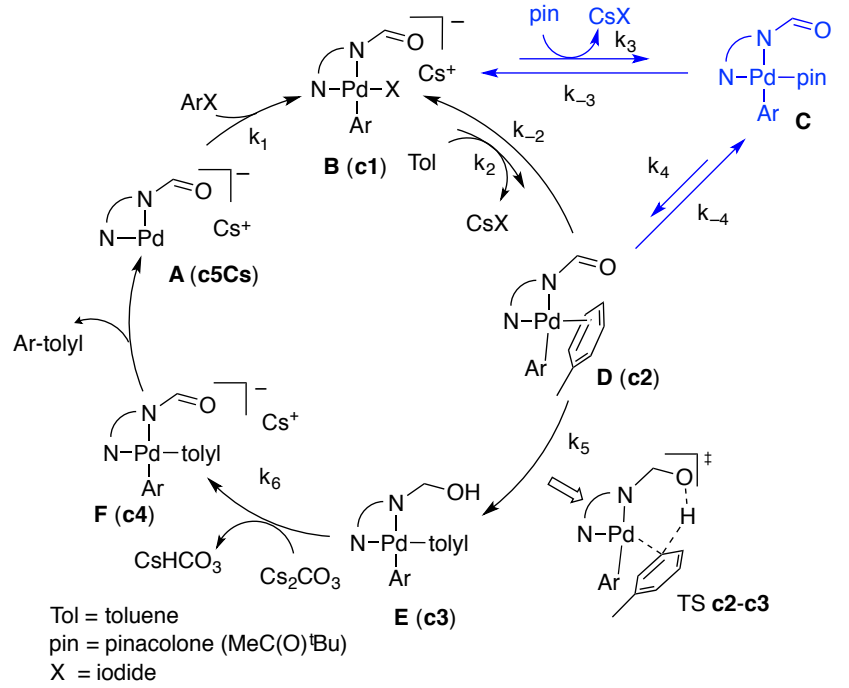

Scheme 6. Proposed catalytic cycle for the arylation of arenes in different solvent media.

The reaction profile in just toluene as solvent (black cycle in Scheme 6) was calculated using DFT methods at the M06 level (see ESI for details), starting from intermediate $B$ since the oxidative addition step (A to B, Scheme 6 ) is fast and kinetically irrelevant (the rate of the reaction is independent on the Arl concentration). Fig. 4 shows a high-energy span in the profile on going form the strongly stabilized ionic complex c1 (B) to the TS corresponding to the $\mathrm{C}-\mathrm{H}$ cleavage assisted by the ligand (TS c2-c3). After that, consistent with the observation of a KIE and an irreversible C-H activation (Eq. 3), the subsequent processes have lower activation energies and should be fast. As shown in Fig. 4, the deprotonation of the ligand followed by reductive elimination is the least energy demanding pathway vs. the reverse order of events, i.e reductive elimination in the neutral complex first (red in Fig. 4).

The relative energies of the basic steps in the profile shown in Fig. 4 fit our experimental observations but the calculated energetic span, $36.4 \mathrm{kcal} \mathrm{mol}^{-1}$, is too high and predicts a much lower conversion rate than the one observed in the catalysis. However, it is important to consider that the concentrations of the species in the experimental conditions are very different from $1 \mathrm{M}$, the standard value used in the calculations, and this is crucial when insoluble cesium salts are formed in the cycle. Microkinetic modeling has proved useful to analyze these situations, ${ }^{27}$ and using the COPASI software the kinetic model shown in Scheme 6 (black) was simulated and the concentration-time evolution was examined. ${ }^{28}$ Experimental initial concentrations were used and the concentration of the halide $(X=1)$ was considered constant throughout the reaction and fixed according to the solubility of $\mathrm{Csl}\left(10^{-4} \mathrm{M}\right)$. The values of $K_{2}\left(K_{2}=k_{2} / k_{-2}\right)$ and $k_{5}$ were calculated from the DFT energy values and the other kinetic constants were given arbitrary values corresponding to fast steps (see ESI for details). ${ }^{29}$ Rate constants $k_{2}$ and $k_{-2}$ were fitted to conform to $K_{2}$ and reproduce the observed conversions. From the microkinetic model the energy profile shown in Fig. 5a can be extracted. 
a)

solvent: toluene/pinacolone
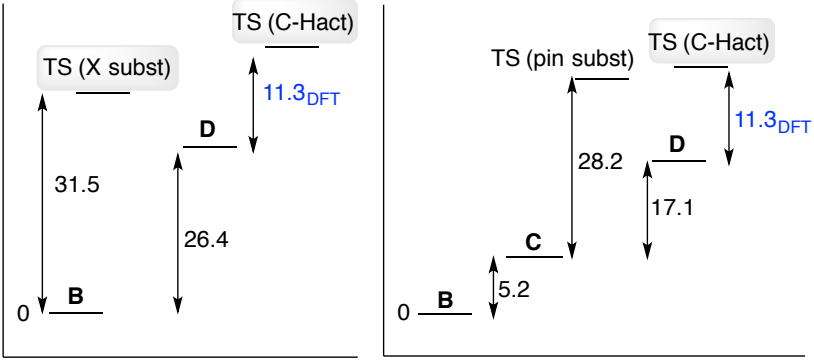

Fig. 5. Free energy profile from microkinetic models for the arylation of toluene in a) toluene as solvent, b) a mixture or toluene/pinacolone $(1 / 1)$.

It shows a rather high-energy transition state for the substitution of toluene for iodide (31.5 kcal mol-1) and just a slightly higher energy difference between $\mathbf{B}$ and $\mathbf{D}$ than the one based on DFT calculations (1.3 kcal mol ${ }^{-1}$ higher). The resting state of the catalyst is the halide complex B (Fig. S41, ESI). Thus, the toluene coordination equilibrium is energetically demanding and controls the concentration of $\mathbf{D}$, influencing the rate of the reaction along with the $\mathrm{C}-\mathrm{H}$ cleavage, the higher energy step, leading to a lower KIE (Eq. 5 and Fig. S42, ESI). Keeping the concentration of free iodide low is crucial to shift the equilibrium $\mathbf{B} \rightleftharpoons \mathbf{D}$ and to the success of the reaction: It is achieved by the formation of an insoluble iodide salt and this is the important role of the cesium cation. If the halide concentration is not fixed in the microkinetic model, it increases as the reaction progresses and makes it very slow. This is shown experimentally and, as mentioned above, the addition of free iodide or the use of a base that leads to a soluble iodide salt, such as $\left(\mathrm{NBu}_{4}\right)_{2} \mathrm{CO}_{3}$, slow the reaction down.

Alkali metal bases, very often cesium salts, are common in palladium-catalyzed $\mathrm{C}-\mathrm{H}$ activation reactions and the role of the cation has been the subject of discussion. ${ }^{30}$ A low free halide (iodide) concentration and its control by the choice of a suitable cation has been found important in other palladium catalytic systems to avoid sequestering the catalyst as palladium iodide. $^{8 c}$ The effect of free halide can be manifold but, in the functionalization of arenes with no-directing groups, its effect in the ligand substitution equilibria is most detrimental.

Considering the same mechanistic framework, the microkinetic simulation for the arylation of toluene in a mixture toluene/pinacolone $=1 / 1$ was carried out. In these conditions, the model needs to include the solvento complex $\mathbf{C}$ and the two equilibria that connect intermediate $\mathbf{C}$ with $\mathbf{B}$ and $\mathbf{D}$ (Scheme 6, black and blue). Experimental initial concentrations were used and the concentration of iodide was fixed according to the solubility of $\mathrm{Csl}$ determined in the solvent mixture $\left(2.4 \times 10^{-4} \mathrm{M}\right.$, see $\left.\mathrm{ESI}\right)$. Based on the experimental value of the equilibrium constant in Scheme $5 \mathrm{~b}$ at $298 \mathrm{~K}\left(1.6 \times 10^{-4}\right)$ a value of $\Delta G_{298}=5.2 \mathrm{kcal} \mathrm{mol}^{-1}$ can be estimated for the analogous equilibrium $\mathbf{B} \rightleftharpoons \mathbf{C}$. Assuming a small entropy change in this equilibrium this $\Delta G$ value was used to determine $K_{3}\left(K_{3}=k_{3} / k\right.$
3) in the simulation at higher temperature. Only the value of $k_{5}$ was taken form DFT calculations, since we observed that the energy difference between c2 (D) and TS c2-c3 is almost insensitive to the solvent (same calculated value in toluene or in acetone: $11.3 \mathrm{kcal}^{\mathrm{mol}^{-1}}$ by DFT). Equilibrium and rate constants $\mathrm{K}_{2}, \mathrm{k}_{4}, \mathrm{k}_{-4}$ were fitted to reproduce the observed conversions. The energy profile that can be deduced from this microkinetic model is shown in Fig. $5 \mathrm{~b} .{ }^{31}$ The concentration change of the different species over time shows that the solvento complex $\mathbf{C}$ is the resting state of the catalyst (Fig. S43, ESI). The use of pinacolone as a co-solvent decreases the energy difference between $\mathbf{B}$ and $\mathbf{D}$, and the overall activation energy of the reaction (from $\mathbf{B}$ to TS(C-Hact) in Fig. 5) in 4.1 $\mathrm{kcal} \mathrm{mol}^{-1}$. This results in the observed acceleration of the process. In this solvent mixture the $\mathrm{C}-\mathrm{H}$ cleavage is the turnover limiting step of the reaction, the toluene coordination exerting a small influence. Thus, the microkinetic model shows a KIE value of 3.2 (Fig. S44), slightly lower than the calculated one (3.64) as it was also observed experimentally (Eq. 5). The reaction in these conditions is less sensitive to the amount of free halide, as observed experimentally and reproduced by the microkinetic model. It is faster even if the solubility of CsI is a bit higher and the amount of free halide is twice the amount than that expected in just toluene. Nonetheless, it is still necessary to generate an insoluble halide since the reaction also slows down upon increase of the free halide concentration above $10 \mathrm{~mol} \%$.

As shown in Table 3 (entries 11-18), the accelerating effect of pinacolone is not observed for the arenes bearing coordinating groups. In these cases the substrate arene could produce both effects observed upon using pinacolone in the toluene arylation i.e. the coordination of the solvent to the metal (intermediate analogous to $\mathbf{C}$ ) and the change in the relative energy of the anionic $\mathbf{B}$ and the neutral intermediate $\mathbf{D}$. If the substituent of the arene is more coordinating than the solvent (a ketone in this case) the presence of the latter will not be important. This occurs for the cyano, ester and amino groups and pyridine. However, the less coordinating ether (anisole, entries 5, 6, Table 3) benefits form the use of the co-solvent. We can speculate that the change in energy of the reaction intermediates upon changing the solvent is more likely to affect the anionic B. Since the polarity or dielectric constant of the medium are not the cause of the observed solvent effect (cf. entries 9 and 10 vs. 13 and 14, Table 3 for arenes with similar polarity), it seems that a hard donor atom $(\mathrm{O}, \mathrm{N}$ in the arene substituents or the solvent) could interact with $\mathrm{Cs}^{+}$and modify the anion-cation interactions in $\mathbf{B}$ and its relative energy as a result. ${ }^{32}$

\section{Conclusions}

The arylation of arenes with no directing groups (non-chelate assisted) can be carried out using the cooperating ligand 2, 2'bipyridin]-6(1H)-one (bipy-6-OH). The success of this transformation is very dependent on the coordination equilibria that control de concentration of the $\pi$-coordinated arene complex. In the arylation of arenes with arylhalides, the 
formation of an insoluble halide salt is crucial for the shift of the halide substitution by arene equilibrium and this is the main beneficial role of the cesium bases (most often carbonate). The study of the arylation of toluene using it as solvent shows that the formation of the arene complex is strongly influencing the reaction rate along with the $\mathrm{C}-\mathrm{H}$ cleavage, it still being the higher-energy transition state in the reaction profile.

The arylation of arenes with non- or weakly coordinating groups can be strongly accelerated by the use of a moderately coordinating solvent (a methyl ketone or an amide) instead of using neat arene, which is a counterintuitive procedure. The study of the arylation of toluene with pinacolone as co-solvent, using microkinetic modeling and stoichiometric studies on model compounds, shows that the presence of the co-solvent changes the resting state of the catalyst from the palladium halide complex to the solvento complex. It also alters the relative energy of the intermediate complexes in the cycle leading to a decrease of the activation energy for the reaction. The $\mathrm{C}-\mathrm{H}$ activation is the most influential rate-determining step.

The use of a co-solvent exerts an acceleration effect and leads to the efficient arylation of non-coordinating arenes but this does not mean that the solvent is inert. In fact, a methyl ketone such as pinacolone undergoes $\mathrm{C}-\mathrm{H}$ activation, which is unproductive since the aryl-enolate coupling $\left(\mathrm{C}\left(\mathrm{sp}^{2}\right)-\mathrm{C}\left(\mathrm{sp}^{3}\right)\right.$ reductive elimination) is slower than the target $\mathrm{C}\left(\mathrm{sp}^{2}\right)-\mathrm{C}\left(\mathrm{sp}^{2}\right)$ coupling. This allows a selective reaction and the possibility of using pinacolone as an unobtrusive reagent. Non-directed arene functionalization is a challenging task and it is difficult to think in suitable reaction media less reactive than the substrate. The results here show that this is not a mandatory requirement since even a more reactive solvent can be extremely useful as long as the byproduct forming step has a substantial kinetic disadvantage. The mechanistic understanding of the steps involved in the catalysis is certainly crucial to be able to make the right choice.

\section{Conflicts of interest}

There are no conflicts to declare.

\section{Acknowledgements}

We acknowledge the financial support of the Spanish MICINN (SGPI, grant CTQ2016-80913-P and PID2019-111406GB-I00), the Junta de Castilla y Leoń (grants VA224P20), and the UVa (fellowship to V.S.).

\section{Notes and references}

1 (a) L. C. Campeau, K. Fagnou, K. Chem. Commun., 2006, 1253-1264. (b) L. Ackermann, R. Vicente, A. R. Kapdi, Angew. Chem. Int. Ed., 2009, 48, 9792-9826. (c) T. W. Lyons, M. S. Sanford, Chem. Rev., 2010, 110, 1147-1169. (d) T. Gensh, M. J. James, T. Dalton, F. Glorius, Angew. Chem. Int. Ed., 2018, 57, 2296-2306.
2 (a) K. M. Engle, T. -S. Mei, M. Wasa, J. -Q. Yu, Acc. Chem. Res., 2012, 45, 788-802. (b) S. R. Neufeldt, M. S. Sanford, Acc. Chem. Res., 2012, 45, 936-946. (c) A. Dey, S. K. Sinha, T. K. Achar, D. Maiti, Angew. Chem. Int. Ed., 2019, 58, 1082010843. (d) Z. Zhang, K. Tanaka, J. -Q. Yu, Nature, 2017, 543, 538-542. (e) H. Shi, Y. Lu, J. Weng, K. L. Bay, X. Chen, K. Tanaka, P. Verma, K. N. Houk, J. -Q. Yu, Nat. Chem., 2020, 12, 399-404.

3 (a) B. -F. Shi, N. Maugel, Y. -H. Zhang, J. -Q. Yu, Angew. Chem. Int. Ed., 2008, 47, 4882-4886. (b) B. -F. Shi, Y. -H. Zhang, J. K. Lam, D. -H. Wang, J. -Q. Yu, J. Am. Chem. Soc., 2010, 132, 460-461. (c) G. Chen, W. Gong, Z. Zhuang, M. S. Andrä, Y. $-Q$. Chen, X. Hong, Y. -F. Yang, T. Liu, K. N. Houk, J. -Q. Yu, Science, 2016, 353, 1023-1027. (d) C. G. Newton, S. G. Wang, C. C. Oliveira, N. Cramer, Chem. Rev., 2017, 117, 8908-8976. (e) T. G. Saint-Denis, R. -Y. Zhu, G. Chen, Q. -F. Wu, J. -Q. Yu, Science, 2018, 359, eaao4798.

4 (a) Y. Yang, J. Lan, J. You, Chem. Rev., 2017, 117, 8787-8863. (b) B. S. Schreib, M. Fadel, E. M. Carreira, Angew. Chem. Int. Ed., 2020, 59, $7818-7822$.

5 (a) J. J. Topczewski, P. J.; Cabrera, N. I. Saper, M. S. Sanford, Nature, 2016, 531, 220-224. (b) J. He, M. Wasa, K. S. L. Chan, Q. Shao, J. -Q., Yu, Chem. Rev., 2017, 117, 8754-8786. (c) Y. - Q. Han, Y. Ding, T. Zhou, S. - Y. Yan, H. Song, B. - F. Shi, J. Am. Chem. Soc., 2019, 141, 4558-4563. (d) K. K. A. Le, H. Nguyen, O. Daugulis, J. Am. Chem. Soc., 2019, 141, 14728-14735.

6 F. -L. Zhang, K. Hong, T. -J. Li, H. Park, J. -Q. Yu, Science 2016, 351, 252-256.

7 (a) N. Kuhl, M. N. Hopkinson, J. Wencel-Delord, F. Glorius, Angew. Chem. Int. Ed., 2012, 51, 10236-10254. (b) A. K. Cook, M. S. Sanford, J. Am. Chem. Soc., 2015, 137, 31093118. (c) S. Kancherla, K. B. Jorgensen, M. A. FernándezIbáñez, Synthesis, 2019, 51, 643-663.

8 (a) M. Lafrance, K. Fagnou, J. Am. Chem. Soc., 2006, 128, 16496-16497. (b) Y. -N. Wang, X. -Q. Guo, X. -H. Zhu, R. Zhong, L. -H. Cai, X. -F. Hou, Chem. Commun., 2012, 48, 10437-10439. (c) C. Arroniz, J. G. Denis, A. Ironmonger, G. Rassias, I. Larrosa, Chem. Sci., 2014, 5, 3509-3514. (d) Y. Tanji, R. Hamaguchi, Y. Tsuji, T. Fujihara, Chem. Commun., 2020, 56, 3843-3846.

9 (a) L. -C. Campeau, S. Rousseaux, K. Fagnou, J. Am. Chem. Soc., 2005, 127, 18020-18021. (b) P. Guo, J. M. Joo, S. Rakshit, D. Same, J. Am. Chem. Soc., 2011, 133, 16338-16341. (c) T. Yan, L. Zhai, M. He, J. -F. Soulé, C. Bruneau, H. Doucet, Adv. Synth. Catal., 2014, 356, 1586-1596. (d) B. -T. Luo, H. Liu, Z. -J. Lin, J. Jiang, D. -S. Shen, R. Z. Liu, Z. Ke, F. -S. Liu, Organometallics, 2015, 34, 4881-4894. (e) J. Kim, S. H. Hong, ACS Catal., 2017, 7, 3336-3343.

10 (a) A. Mondal, H. Chen, L. Flämig, P. Wedi, M. van Gemmeren, J. Am. Chem. Soc., 2019, 141, 18662-18667. (b) A. Das, A. Jana, B. Maji, Chem. Commun., 2020, 56, 42844287. (c) T. M. Levesque, R. G. Kinney, B. A. Arndtsen. Chem. Sci., 2020, 11, 3104-3109.

11 (a) D. Whitaker, J. Burés, I. Larrosa, J. Am. Chem. Soc., 2016, 138, 8384-8387. (b) S. Y. Lee, J. F. Hartwig, J. Am. Chem. Soc., 2016, 138, 15278-15284. (c) M. D. Lotz, N. M. Camasso, A. J. Canty, M. S. Sanford, Organometallics, 2017, 36, 165-171. (d) C. Colletto, A. Panigrahi, J. Fernández-Casado, I. Larrosa, J. Am. Chem. Soc., 2018, 140, 9638-9643. (e) M. Batuecas, J. Luo, I. Gergelitsová, K. Krämer, D. Whitaker, I. J. VitoricaYrezabal, I. Larrosa, ACS Catal., 2019, 9, 5268-5278. (f) A. Panigrahi, D. Whitaker, I. J. Vitorica-Yrezabal, I. Larrosa, ACS Catal., 2020, 10, 2100-2107. (g) Y. Shimoyama, J. Kuwabara, T. Kanbara, ACS Catal., 2020, 10, 3390-3397.

12 (a) M. Lafrance, D. Shore, K. Fagnou, Org. Lett., 2006, 22, 5097-5100. (b) F. Chen, Q. Q. Min, X. Zhang, J. Org. Chem., 
2012, 77, 2992-2998. (c) S. Mao, X. Shi, J. -F. Soulé, H. Doucet, Chem. Eur. J., 2019, 25, 9504-9513.

13 V. Salamanca, A. C. Albéniz, Eur. J. Org. Chem., 2020, 32063212.

14 V. Salamanca, A. Toledo, A. C. Albéniz, J. Am. Chem. Soc., 2018, 140, 17851-17856

15 (a) P. Wang, P. Verma, G. Xia, J. Shi, J. X. Qiao, S. Tao, P. T. W. Cheng, M. A. Poss, M. E. Farmer, K. -S. Yeung, J. -Q. Yu, Nature, 2017, 551, 489-494. (b) Z. Fan, K. L. Bay, X. Chen, Z. Zhuang, H. S. Park, K. - S. Yeung, K. N. Houk, J. -Q. Yu, Angew. Chem. Int. Ed., 2020, 59, 4770 -4777.

16 Q. Shao, K. Wu, Z. Zhuang, S. Qian, J. -Q. Yu, Acc. Chem. Res., 2020, 53, 833-851.

17 D. L. Davies, S. A. Macgregor, C. L. McMullin, Chem. Rev., 2017, 117, 8649-8709.

18 (a) E. Clot, O. Eisenstein, N. Jasim, S. A. Macgregor, J. E. Mcgrady, R. N. Perutz, Acc. Chem. Res., 2011, 44, 333-348. (b) O. Eisenstein, J. Milani, R. N. Perutz, Chem. Rev., 2017, 117, 8710-8753.

19 J. A. Molina de la Torre, P. Espinet, A. C. Albéniz, Organometallics, 2013, 32, 5428-5434.

20 (a) D. Prat, A. Wells, J. Hayler, H. Sneddon, C. R. McElroy, S. Abou-Shehadad, P. J. Dunn, Green Chem., 2016, 18, 288-296. (b) F. P. Byrne, B. Forier, G. Bossaert, C. Hoebers, T. J. Farmer, A. J. Hunt, Green Chem., 2018, 20, 4003-4011.

21 C. Reichardt, Chem. Rev., 1994, 94, 2319-2358.

22 M. Pérez-Rodríguez, A. A. C. Braga, M. García-Melchor, M. H. Pérez-Temprano, J. A. Casares, G. Ujaque, A. R. de Lera, R. Álvarez, F. Maseras, P. Espinet, J. Am. Chem. Soc., 2009, 131, 3650-3657.

23 A. C. Albéniz, N. M. Catalina, P. Espinet, R. Redón, Organometallics, 1999, 18, 5571-5576.

24 E. M. Simmons, J. F. Hartwig, Angew. Chem. Int. Ed., 2012, 51, 3066-3072.

25 (a) P. Espinet, A. C. Albéniz, J. A. Casares, J. M. Martínezllarduya, Coord. Chem. Rev., 2008, 252, 2180-2208. (b) A. C. Albéniz, P. Espinet, Y. Jeannin, M. Philoche-Levisalles, B. Mann, J. Am. Chem. Soc., 1990, 112, 6594-6600. (c) A. L. Casado, P. Espinet, A. M. Gallego, J. M. Martínez-llarduya, Chem. Commun., 2001, 339-340. (d) A. C. Albéniz, P. Espinet, P.; B. Martín-Ruiz, D. Milstein, J. Am. Chem. Soc., 2001, 123, 11504-11505.

26 Complex 6 was identified by comparison of its ${ }^{19} \mathrm{~F}$ NMR spectrum with that of an authentic sample prepared as reported in ref. 14.

27 M. Besora, F. Maseras, WIREs Comput Mol Sci., 2018, 8, e1372.

28 COmplex PAthway Simulator (COPASI) is an easily available free software. S. Hoops, S. Sahle, R. Gauges, C. Lee, J. Pahle, N. Simus, M. Singhal, L. Xu, P. Mendes, U. Kummer, Bioinformatics, 2006, 22, 3067-3074.

29 Microkinetic simulations were carried out using either a high value $k_{6}$ for the overall transformation $\mathbf{E}$ to $\mathbf{A}$ or including explicitly the deprotonation step (E to $\mathbf{F}$ ) in the model and the rate constant derived from the DFT deprotonation barrier (see ESI). As predicted by the DFT calculations, the deprotonation step is kinetically irrelevant and the amount of base present does not affect the reaction rate.

30 L. -P. Xu, B. E. Haines, M. J. Ajitha, K. Murakami, K. Itami, D. G. Musaev, ACS Catal., 2020, 10, 3059-3073.

31 DFT calculations could not be performed in the actual toluene/pinacolone solvent mixture to compare the relative energies of intermediates B-D with those obtained from the microkinetic model in Fig. 5b. Nonetheless, the microkinetic simulation is very sensitive to the values of $K_{2}$ and $k_{4}, k_{-4}$ (small changes make a huge difference in the conversiontime curves) leading to a resulting model with a high level of confidence.
32 Regardless its low charge to radius ratio, $\mathrm{Cs}^{+}$is a hard acid, as all the other alkali metal cations. Both the chemical behavior and the hardness parameters identify this closed shell cation as hard: (a) A. F. Holleman, E. Wiber "Inorganic Chemistry", Academic Press, 2001, p. 229. (b) G. L. Miessler, D. A. Tarr, "Inorganic Chemistry", $2^{\text {nd }}$ Ed. Prentice-Hall, 1999. (c) H. Xu, D. C. Xu, Y. Wang, ACS Omega, 2017, 2, 7185-7193. 